\title{
As câmaras municipais e o poder local: Vila Rica - um estudo de caso na produção acadêmica de Maria de Fátima Silva Gouvêa ${ }^{*}$
}

\author{
Júnia Ferreira Furtado*
}

Para minha amiga, que muita falta faz.

Este artigo, a partir de um ligeiro percurso por alguns dos trabalhos produzidos por Maria de Fátima Silva Gouvêa acerca do papel das câmaras municipais enquanto instituições de poder local na América portuguesa, analisa a contribuição da autora sobre o tema, tomando como eixo norteador da análise seu estudo acerca do Senado da Câmara de Vila Rica, publicado, em 2004, na Revista Varia Historia em seu volume 31. O artigo, intitulado Dos poderes de Vila Rica do Ouro Preto - notas preliminares sobre a organização político-administrativa na primeira metade do século XVIII, integrou o dossiê Vila Rica do Pilar: reflexões sobre Minas Gerais e a época Moderna, organizado por Adalgisa Arantes Campos, Douglas Cole Libby e Renato Franco. Palavras-chave: Câmaras municipais - Poder local - Administração

The town councils and the local power: Vila Rica - a case study in Maria de Fátima Silva Gouvêa's historical analyses

This article, based on a brief analysis of some of the works produced by Maria de Fátima Silva Gouvêa about the role of the town councils in Portuguese America, examines the author's contribution on the subject. The leading point of such analysis

\footnotetext{
* Artigo recebido e aprovado para publicação em junho de 2009.

** Professora Associada do Departamento de História da UFMG. E-mail: juniaf@ufmg.br.
} 
is her study on the Vila Rica Town Council published at volume 31 of Varia Historia magazine in 2004. The article, entitled The Powers of Vila Rica do Ouro Preto - preliminary notes on the political and administrative organization in the first half of the XVIII century, was part of the file Vila Rica do Pilar: Reflections on Minas Gerais and the Modern Era organized by Adalgisa Campos Arantes, Douglas Cole Libby and Renato Franco.

Keywords: Town Councils - Local Powers - Administration

Les conseils municipaux et le pouvoir local: Vila Rica - une étude de cas dans la production académique de Maria de Fatima Silva Gouvêa

Cet article, à partir d'un parcours ébauché par quelques uns des travaux réalisés par Maria de Fatima Silva Gouvêa sur le rôle des conseils municipaux comme institutions du gouvernement local dans l'Amérique Portugaise, examine la contribution de l'auteur sur ce thème, sous la forme d'une analyse, dont la ligne maîtresse est son étude sur le Sénat de Administration de Vila Rica, publié en 2004 dans la revue Varia Historia (volume 31). L'article, intitulé Des pouvoirs de Vila Rica do Ouro Preto Notes préliminaires sur l'organisation politique et administrative au cours de la première moitié du XVIIIe siècle, intègre le dossier Vila Rica do Pilar: réflexions sur Minas Gerais et les temps modernes, organisé par Adalgisa Campos Arantes, Douglas Cole Libby et Renato Franco.

Mots-clés: Ville - Le Pouvoir Local - l'Administration

O ano de 2002 representou uma inflexão nas diretrizes esboçadas para a Revista Varia Historia, publicação do Programa de Pós-graduação em História da UFMG. Na ocasião, foram definidos novos rumos para o periódico e optou-se pela constituição de dossiês temáticos, a serem organizados pelos professores/pesquisadores da casa, agregados nas diversas linhas de pesquisa constituintes do referido Programa. ${ }^{1}$ Pouco depois, após intenso debate, o Conselho Editorial aprovou e agendou os primeiros dossiês que seriam publicados nos anos vindouros. Uma das escolhas recaiu sobre a Professora Adalgisa Arantes Campos que, desde 1999, organizava um Banco de Dados referente às séries paroquiais da Freguesia de Nossa Senhora do Pilar do Ouro Preto, abrangendo os séculos XVIII e XIX. Trata-se de um data base que arrola séries de registros de batismos, casamento e óbitos pertencentes à paróquia do Pilar, uma das duas de que Vila Rica era constituída, a partir dos microfilmes exis-

\footnotetext{
${ }^{1}$ Disponível em: http://www.fafich.ufmg.br/varia/apresentacao (acesso em 20/05/2009).
} 
tentes na Casa dos Contos. ${ }^{2}$ Especialistas foram convidados a escrever sobre os mais diversos temas, tais como o papel e o alcance do batismo, dos laços de compadrio, dos cerimoniais de morte e enterramento na sociedade de Vila Rica, tendo como fonte principal os dados disponibilizados pelos organizadores. O dossiê intitulado Vila Rica do Pilar: reflexões sobre Minas Gerais e a época Moderna foi publicado em 2004 e agregou diversos autores de renome. ${ }^{3}$

Mas o dossiê não se restringiu à análise dos dados seriais contidos no Banco de Dados. Tratava-se também de dar o pano de fundo sobre o qual se assentavam os estudos sobre aquela localidade. Qual era o papel dos registros paroquiais no contexto dos estudos históricos? Qual o significado do batismo e da morte no interior dos ritos e crenças católicas? Como era e se organizava a sociedade e a administração daquele núcleo urbano? Ao se deparar com esse último ponto, o grupo organizador do dossiê, em consonância com o Comitê Editorial, apontou o nome de Maria de Fátima Silva Gouvêa, como o mais indicado para redigir uma reflexão acerca da política e da administração local. Intitulado Dos poderes de Vila Rica do Ouro Preto - notas preliminares sobre a organização político-administrativa na primeira metade do século XVIII, o texto por ela produzido para integrar o referido dossiê tem como eixo central o exame do papel e da composição da Câmara Municipal de Vila Rica, enquanto instância local do sistema administrativo implantado pelos portugueses na América. ${ }^{4}$

O presente artigo, a partir de um ligeiro percurso por alguns dos trabalhos produzidos por Maria de Fátima Gouvêa acerca das câmaras municipais e do poder local na América portuguesa, analisa a contribuição da autora sobre estes temas, tomando como eixo norteador e ponto de chegada da análise este seu estudo acerca do Senado da Câmara de Vila Rica, publicado em 2004 na Revista Varia Historia.

\footnotetext{
${ }^{2}$ Adalgisa Arantes Campos, "Apresentação", Varia Historia, v. 31, Belo Horizonte, jan. 2004, p. 7-8.

${ }^{3}$ Adalgisa Arantes Campos, Douglas Cole Libby e Renato Franco (orgs.), "Vila Rica do Pilar: reflexões sobre Minas Gerais e a época Moderna", Varia Historia, v. 31, Belo Horizonte, jan. 2004, p. 7-206.

${ }^{4}$ Maria de Fátima Silva Gouvêa, "Dos poderes de Vila Rica do Ouro Preto - notas preliminares sobre a organização político-administrativa na primeira metade do século XVIII", Varia Historia, v. 31, Belo Horizonte, jan. 2004, p. 120-140.
} 


\section{Entre o Império das provincias e o das câmaras municipais}

A escolha de Maria de Fátima Gouvêa para assumir a tarefa de analisar a esfera administrativa local implantada pela Coroa portuguesa em Vila Rica, no século XVIII, foi respaldada pelas instigantes análises que vinham sendo por ela produzidas no sentido de verticalizar o estudo das relações de poder e das formas de governação encetadas pela metrópole portuguesa em sua conquista na América.

Seu interesse pelo tema do papel das relações de poder e da administração é evidenciado desde sua dissertação de mestrado, intitulada The Brazilian Chamber of Deputies' debate over the passing of the freebirth law of $1871 .{ }^{5} \mathrm{Mas}$ foi em sua tese de doutorado, O Império das Províncias: Rio de Janeiro 1822-1889, que este interesse se delineou com mais clareza, apontando desde já as principais linhas interpretativas e temáticas que norteariam seus trabalhos a seguir. Sua tese versou sobre o exercício da política provincial durante o período imperial. Defendida em 1989, na Universidade de Londres, somente no ano passado a tese foi finalmente vertida para o português e publicada em livro. ${ }^{6}$ Neste texto, cuja análise se centra no Império brasileiro, já estavam esboçados vários dos temas que se tornariam vértices de suas análises posteriores, tais como a relação entre os poderes locais e o central, o papel das câmaras municipais e das elites na governação do Império e a formação e a articulação das redes clientelares de poder inseridas nos órgãos administrativos.

$\mathrm{Na}$ tese, ao refletir sobre os espaços de atuação política no interior do Império no Brasil, Maria de Fátima salienta "uma significativa descontinuidade [que] deve ser observada em relação ao período colonial, na medida em que se haviam constituído espaços de representação dos interesses regionais/ provinciais, o que no período colonial se restringia ao âmbito das célebres câmaras". ${ }^{7}$ Ou seja, se o espaço mais dinâmico de poder imperial residia na Província, como bem perceberam autores coevos citados pela autora, no período colonial tal prerrogativa coubera às câmaras municipais. Ela concluiu que, com a legislação imperial, estas últimas se tornaram totalmente dependentes

\footnotetext{
${ }^{5}$ Maria de Fátima Silva Gouvêa, The Brazilian Chamber of Deputies' debate over the passing of the freebirth law of 1871, Londres, Institute of Latin American Studies, 1994 (Dissertação, Mestrado em História).

${ }^{6}$ Maria de Fátima Silva Gouvêa, O império das províncias: Rio de Janeiro 1822-1889, Rio de Janeiro, Civilização Brasileira/Fapesp, 2008.

${ }^{7}$ Maria de Fátima Silva Gouvêa, "Apresentação", in: O império das províncias: Rio de Janeiro 1822-1889, p. 11.
} 
da administração provincial e "apenas algumas eram capazes de manter algum controle sobre o gerenciamento das questões locais”. Seriam estas as que conseguiram garantir alguma autonomia financeira. ${ }^{8}$

Se este estudo se debruçara sobre a esfera provincial, elegendo o caso do Rio de Janeiro, a partir de sua dupla articulação com os poderes locais e o central, a partir daí, um dos temas que vai despertar o interesse de Maria de Fátima e merecerá vários estudos será o das câmaras municipais enquanto instituição de poder local. Como advertira na tese com perspicácia, foi no contexto do período colonial, enquanto instâncias integrantes da administração do Império português, que as câmaras assistiram a uma maior autonomia e abrangência de atuação, e não no período imperial, quando, ao contrário, houve uma drástica redução de sua ação, cerceada pelo poder provincial. Ao escolher o tema das câmaras e do poder local como seu próximo objeto de estudo, devido ao fato de reconhecer que o dinamismo destas instituições ocorrera na colônia, nada mais natural que, apesar deste debut no período imperial, fosse sobre a América portuguesa que Maria de Fátima Gouvêa concentrasse a maior parte da produção acadêmica que se seguiu ao seu doutoramento.

\section{As câmaras municipais e o poder local - o caso do Rio deJaneiro}

Para acompanharmos a trajetória analítica de Maria de Fátima Gouvêa que veio à luz sobre o papel das câmaras municipais, tomar-se-á como ponto de partida seu artigo publicado na Revista Brasileira de História, sob o título Homens bons do Rio de Janeiro, ca.1790-1822.9 O texto destaca como tema de estudo a conformação do poder local na cidade do Rio de Janeiro, na virada do século XVIII para o XIX. Para a autora, a cidade do Rio surge como um lugar singular que ocupa "um papel chave como núcleo da região sudeste numa conjuntura mutante, e cabeça do Império colonial português em sua fase de eclipse". Essa área, desde o período pombalino, "fora cada vez mais identificada como o centro mais importante da América portuguesa". ${ }^{10}$

É na urbe do Rio de Janeiro e nesse momento em particular que, segundo Maria de Fátima, se articulam, de um lado, o vértice do eixo econômico do Império, a partir do tráfico transatlântico de escravos e do comércio ${ }^{8}$ Maria de Fátima Silva Gouvêa, "Câmaras municipais", in: O império das províncias: Rio de Janeiro 1822-1889, p. 115.

${ }^{9}$ Maria de Fátima Silva Gouvêa, "Homens bons do Rio de Janeiro, ca.1790-1822", Revista Brasileira de História, São Paulo, v. 18, n. 36, 1998, p. 297-330.

${ }^{10}$ Maria de Fátima Silva Gouvêa, "Homens bons do Rio de Janeiro, ca.1790-1822”, p. 298. 
mais amplo a ele associado, e, de outro, a formação do súdito colonial que se estabelecia na tensão entre a nobreza da terra com suas demandas locais e a administração colonial como um todo. ${ }^{11}$ É no interior dessas tensões entre o poder central e o local que as câmaras municipais emergem, desempenhando um papel fulcral como articuladoras dos dois níveis de poder. As relações de poder no Rio de Janeiro, vistas a partir da articulação dos homens bons em torno da câmara local, surgem no interior de sua análise como um estudo de caso que, como ela mesmo sugere, deveria contribuir para iluminar e instigar novas análises sobre o tema nas demais regiões brasileiras. O estudo das câmaras municipais constituirá, a partir deste artigo, uma das pedras angulares de suas análises sobre a governação portuguesa no Brasil, enquanto parte integrante do Império português.

Seu artigo Homens bons do Rio de Janeiro toma como eixo teórico norteador "uma leitura crítica da dinâmica das relações de poder travadas no mundo colonial" em consonância com uma recente corrente historiográfica, tanto em sua vertente portuguesa quanto na brasileira, que tem como ponto de partida a ideia de constituição de um Império luso brasileiro. ${ }^{12}$ Para tanto, inicia com a crítica à análise clássica de Caio Prado Jr., em Formação do Brasil Contemporâneo, de 1942, que sustenta a existência de uma oposição intrínseca entre a colônia e a metrópole. Na contramão deste axioma, interessa à autora focar nas relações de poder que se constituem entre a colônia e a metrópole, não no sentido da exclusão, mas as que permitiram que os súditos desfrutassem de um sentimento de pertencimento ao Império português. ${ }^{13}$

Seu texto se centra na análise da composição da Câmara Municipal do Rio de Janeiro e de como os homens bons da cidade se articularam no interior dessa instituição. Para além do perfil socioeconômico dessa elite camarária, onde proliferam senhores de engenho e negociantes de grosso trato, Maria de Fátima aponta como aspecto articulador do acesso à câmara o fato desses indivíduos pertencerem às redes clientelares, cujas relações eram preponderantemente familiares, conformando uma "teia endogâmica" ${ }^{14}$ É nesse ponto $\underline{\text { que reside a grande contribuição do artigo à historiografia que versa sobre as }}$ ${ }^{11}$ Maria de Fátima Silva Gouvêa, "Homens bons do Rio de Janeiro, ca.1790-1822", p. 298299.

${ }^{12}$ Maria de Fátima Silva Gouvêa, "Homens bons do Rio de Janeiro, ca.1790-1822", p. 301306.

${ }^{13}$ Maria de Fátima Silva Gouvêa, "Homens bons do Rio de Janeiro, ca.1790-1822", p. 300.

${ }^{14}$ Maria de Fátima Silva Gouvêa, "Homens bons do Rio de Janeiro, ca.1790-1822", p. 319321. 
relações de poder e a administração no seio do Império português, pois sua análise aponta para a inserção das elites administrativas locais, a partir dos postos alcançados no interior das câmaras municipais, às redes hierárquicas de poder que se estendem por todo o Império. Esse conceito de teia endogâmica ou rede de interesse permeará, a partir de então, as futuras análises da autora sobre as relações de poder que se estendem por todo o Império português.

\section{As câmaras e a economia do bem comum}

Em 2000, sai publicado na Revista Penélope um artigo de coautoria de Maria de Fátima Gouvêa, parceria com Maria Fernanda Bicalho e João Fragoso. Fruto do produtivo intercâmbio intelectual e acadêmico deste grupo, o qual se estenderá ao longo dos próximos anos, ${ }^{15}$ ele contém algumas análises que são fundamentais para se compreender as interpretações de Maria de Fátima acerca das instituições camarárias. ${ }^{16}$

O texto apresenta o conceito de economia do bem comum como articulador tanto da formação, quanto das práticas da sociedade colonial, esta inserida no Império português à época Moderna e, por isso, gestada num contexto de Antigo Regime. A economia do bem comum agrega um conjunto de práticas relativas a uma sociedade de privilégios, que se assenta na concessão de mercês pelo rei a grupos restritos de indivíduos, encerrados em cadeias hierárquicas, que passam a partir dessas concessões a deter postos chaves na administração do Império, incluindo aí as câmaras municipais, enquanto instâncias de poder local. Estes postos, por sua vez, permitem que estes mesmos grupos encetem um conjunto de práticas econômicas, de base monopolistas e discricionárias, que reverte seus fins para si próprios, reforçando ainda mais seu caráter de privilegiados. Os indivíduos relacionam-se entre si no interior destes grupos a partir de redes de clientela, assentadas em hierarquias e distinções, cujo vértice se origina no próprio rei.

As câmaras municipais se articulam no interior da administração do Império enquanto espaços fundamentais da República para a gestão da economia do bem comum. Isso porque é no interior dessa instituição que os grupos

${ }^{15} \mathrm{O}$ ponto alto desta parceria foi a publicação do livro: João Fragoso, Maria de Fátima Silva Gouvêa e Maria Fernanda Baptista Bicalho (orgs.), O Antigo Regime nos trópicos: a dinâmica imperial portuguesa, séculos XVI-XVII, Rio de Janeiro, Civilização Brasileira, 2001.

${ }^{16}$ João Fragoso, Maria de Fátima Silva Gouvêa e Maria Fernanda Baptista Bicalho, "Uma leitura do Brasil colonial: bases da materialidade e da governabilidade no império", Penélope, Revista de História e Ciências Sociais, Lisboa, v. 23, p. 67-88, 2000. 
locais - leiam-se elites ou bandos ${ }^{17}$ - encontram espaços de reconhecimento e ascensão social. Mas, não só; elas são fundamentais para que tais grupos articulem um conjunto de práticas econômicas, a partir das prerrogativas detidas por este órgão, e dessa forma "intervinham no mercado controlando os preços e serviços ligados ao abastecimento da cidade". ${ }^{18}$

As câmaras, nesta perspectiva, se apresentam como locais fundamentais capazes de articular interesses em prol do bem comum, garantindo, por exemplo, o abastecimento de certos gêneros, ou a cobrança do preço justo. Porém, a ideia de bem comum se trata antes de tudo de um discurso generalizador e universalista, pois os grandes beneficiários dessas políticas são as próprias elites detentoras dos cargos que "retiravam do mercado e da livre concorrência bens e serviços indispensáveis ao público, passando a ter sobre eles o exercício da gestão". O que se efetiva, na realidade, é "um mercado regulado pela política". ${ }^{19}$

O artigo também aponta para a generalização da instituição camarária por todo o Império português, que se tornou fundamental para a sua governabilidade. Invocando Charles Boxer, os autores destacam que, desde Macau, passando pelo Rio de Janeiro e até Lisboa, as câmaras foram "instituições fundamentais na construção e na manutenção do Império Ultramarino”. Elas se tornaram importantes locus de negociação entre os interesses locais e o central e se constituíram como o "principal espaço de exercício da cidadania no Antigo Regime". ${ }^{20}$

\section{“As mutantes instituições camarárias"}

Se por um lado, nos seus diversos estudos, Maria de Fátima Gouvêa chama a atenção para o fato de que as câmaras se generalizaram por todo o Império português, onde se constituíram como espaços privilegiados de

\footnotetext{
${ }^{17}$ João Luis Ribeiro Fragoso, "A nobreza vive em bandos: a economia política das melhores famílias da terra do Rio de Janeiro, século XVII", Tempo, Revista do Departamento de História da UFF, Niterói, v. 8, n. 15, p. 11-35, 2003.

${ }^{18}$ João Fragoso, Maria de Fátima Silva Gouvêa e Maria Fernanda Baptista Bicalho, "Uma leitura do Brasil colonial: bases da materialidade e da governabilidade no império", p. 70.

19 João Fragoso, Maria de Fátima Silva Gouvêa e Maria Fernanda Baptista Bicalho, "Uma leitura do Brasil colonial: bases da materialidade e da governabilidade no império", p. 71.

${ }^{20}$ João Fragoso, Maria de Fátima Silva Gouvêa e Maria Fernanda Baptista Bicalho, "Uma leitura do Brasil colonial: bases da materialidade e da governabilidade no império", p. 75-76.

${ }^{21}$ Tomo a expressão do artigo: Maria de Fátima Silva Gouvêa, "Poder, autoridade e o Senado da Câmara do Rio de Janeiro, ca.1780-1820”, Tempo, Niterói, v. 7, n. 13, p. 112, 2002.
} 
governação sob bases contratualistas entre súditos e governantes; por outro lado, ela não deixa de salientar a importância de se ater ao estudo de cada caso em particular, no interior de sua própria temporalidade e espacialidade. Para acentuar o caráter singular de cada uma delas, ela as qualifica como "mutantes instituições camarárias". Por essa razão, em 2002, a Câmara do Rio de Janeiro é retomada como eixo para aprofundar sua análise sobre estas instituições, novamente no contexto entre 1780-1820, temporalidade que abarca o período que precede e o do próprio estabelecimento da Família Real na cidade. ${ }^{22}$

A autora aponta como justificativa para ali centrar seu estudo no fato de que

a Câmara do Rio de Janeiro tem sido considerada como um exemplo importante da forma original como a Coroa portuguesa concedeu significativas somas de autonomia governativa à instituição camarária, a despeito do progressivo aumento do número de instituições da alta administração instaladas na cidade ao longo do século XVIII e início do XIX. ${ }^{23}$

E, ao longo do texto, esclarece que esta originalidade é resultante da forma paradoxal pela qual se caracterizou a atuação deste senado municipal no período. Assistiu-se, por um lado, ao aumento de seu poder e de seu prestígio e, por outro, à restrição de sua capacidade governativa no espaço da cidade. Isso foi possível porque se observou que a instituição dispôs de relativa autonomia para atuar no espaço da urbe, sendo requisitada a propor medidas para melhorar o abastecimento - especialmente da carne verde -, efetivar a cobrança ou suspensão de impostos, organizar festividades etc., agindo ativamente dentro do escopo de suas atribuições. Além disso, houve uma progressiva diminuição da amplitude dessas mesmas atribuições, especialmente no caso da atuação do Juiz de Fora, com a criação de outros poderes concorrentes, como o do Intendente de Polícia ou o do Auditor das Tropas da Corte e da Província. A criação desses cargos fez aumentar as disputas de jurisdição entre estas esferas de poder. ${ }^{24}$ No mesmo período, ocorreu também

${ }^{22}$ Maria de Fátima Silva Gouvêa, "Poder, autoridade e o Senado da Câmara do Rio de Janeiro, ca.1780-1820”, Tempo, Niterói, v. 7, n. 13, p. 111-115, 2002.

${ }^{23}$ Maria de Fátima Silva Gouvêa, "Poder, autoridade e o Senado da Câmara do Rio de Janeiro, ca.1780-1820", p. 113.

${ }^{24}$ Em outro artigo seu, Maria de Fátima Gouvêa destaca que tal escalada nas disputas de jurisdição com outras instituições havia sido até então característica da Câmara de Lisboa, apontando para a importância da proximidade do poder central para o fenômeno, atestando a centralidade do Rio de Janeiro no período. Maria de Fátima Silva Gouvêa, "As bases institucionais da construção da unidade. Dos poderes do Rio Joanino: administração e governabilidade no império luso-brasileiro”, in: Istvan Jancsó (org.), Independência: história e historiografia, São Paulo, Hucitec, 2005, p. 713. 
uma maior interferência do poder central na instituição, passando a Coroa a ser responsável, por exemplo, pela indicação do presidente da instituição em caso de vacância por morte. ${ }^{25}$

Mas esta contradição é principalmente aparente, como nos adverte Maria de Fátima, pois durante o mesmo período a Câmara do Rio de Janeiro se tornou importante local para a representatividade das elites, que buscavam espaços de atuação hierarquicamente privilegiados. No período abrangido, mais do que anteriormente, ocupar postos nessa instituição qualificou estes homens e aproximou-os, como nunca, do centro do poder régio. Assim, observa-se que, por essa época, os principais ocupantes dos cargos de Juiz de Fora e Presidente do Senado foram homens de prestígio e qualidade, apontando para a importância desse espaço como forma de promoção e dignificação social. ${ }^{26}$ Outro aspecto importante destacado foi o fato de que a própria Câmara do Rio de Janeiro, enquanto instituição propriamente dita, ocupou um papel de poder proeminente na hierarquização existente entre as demais câmaras dispersas pelo Império. Este lugar tinha sido até então ocupado pelo Senado da cidade de Lisboa. Isto não só a dignificava enquanto instituição, imprimindo-lhe maior capacidade de negociação com o poder central, como enaltecia mais ainda seus próprios ocupantes.

\section{Dos poderes na Vila Rica de Ouro Preto}

Como se percebe pelas características dos estudos sobre o poder local, produzidos por Maria de Fátima Gouvêa até então, aqui brevemente analisados, o convite para que ela produzisse um trabalho acerca da Câmara de Vila Rica se constituía como um desdobramento natural de sua produção acadêmica sobre o tema, mas era, ao mesmo tempo, um desafio. Desafio por se tratar de um espaço geográfico com o qual ela nunca trabalhara; pelo fato de existir uma, ao mesmo tempo, tradicional e pujante historiografia sobre a capitania de Minas Gerais durante o século XVIII, com a qual era forçoso dialogar; por abarcar uma temporalidade bastante dilatada (pelo menos um século) e por exigir o mergulho em uma documentação específica sobre a qual ela nunca se debruçara anteriormente. E foi como desafio, revestido de muita alegria e

\footnotetext{
${ }^{25}$ Maria de Fátima Silva Gouvêa, "Poder, autoridade e o Senado da Câmara do Rio de Janeiro, ca.1780-1820", p. 112-123.

${ }^{26}$ Maria de Fátima Silva Gouvêa, "Poder, autoridade e o Senado da Câmara do Rio de Janeiro, ca.1780-1820”, p. 124.
} 
entusiasmo, que ela abraçou a tarefa, satisfeita por ter sido uma carioca a ser escolhida pela Varia Historia a se aventurar pelas Minas do Ouro.

Com modéstia, ela intitulou o artigo de Notas Preliminares e anunciou que se tratava de um texto prospectivo sobre o tema. Logo no resumo, salientou que seu principal objetivo era "avaliar os principais desafios suscitados pelo estudo da organização político-administrativa de Vila Rica do Ouro Preto no século XVIII". ${ }^{27}$ Estabeleceu então sua estratégia para esmiuçar sua análise. Tratava-se de: 1) fazer uma análise do panorama geral do processo histórico de organização político-administrativa que acompanhou a ocupação da capitania a partir de fins do século XVII, articulando esse processo ao de constituição das vilas e implantação das câmaras em Minas Gerais, especialmente Vila Rica; 2) realizar um levantamento historiográfico sobre o tema, dialogando principalmente com os novos estudos acerca das relações de poder e da administração na capitania; 3) identificar questões e temas que permitissem um melhor entendimento do tema, sugerindo possibilidades de estudo.

Ela introduziu o tema apontando para o fato de que se, por um lado, a capitania de Minas Gerais, centro econômico do Império português nos setecentos, vinha sendo objeto de análise de parte dos novos estudos que reinterpretavam de maneira instigante e inovadora a questão das relações de poder; por outro, a temática das instituições camarárias, especialmente a de Vila Rica, não havia merecido igual atenção. Destaca o fato de que o pioneiro e conhecido estudo de A. J. Russell-wood, produzido em 1977, sobre o poder local na América portuguesa focara exatamente o caso da Câmara de Vila Rica, ${ }^{28}$ mas que, paradoxalmente, isto não fora capaz de despertar o aparecimento de novos trabalhos que verticalizassem o seu estudo.

Cabe destacar que, em linhas gerais, Maria de Fátima Gouvêa tinha razão em apontar esta carência. Mas pelo menos três trabalhos não referenciados em seu artigo, apesar de não serem específicos sobre a atuação das câmaras municipais, trouxeram contribuições importantes para o tema e, por isso, merecem atenção. Um deles é o livro Des terres aux villes de l'or, de Cláudia Damasceno Fonseca, ${ }^{29}$ que analisa o processo de ocupação da capita-

\footnotetext{
${ }^{27}$ Maria de Fátima Silva Gouvêa, "Dos poderes de Vila Rica do Ouro Preto - notas preliminares sobre a organização político-administrativa na primeira metade do século XVIII”, p. 121.

${ }^{28}$ A. J. Russell-wood, "O governo local na América portuguesa: um estudo de divergência cultural”, Revista de História, São Paulo, v. LV, n. 109, ano XXVIII, p. 25-79, 1977.

${ }^{29}$ Cláudia Damasceno Fonseca, Des terres aux villes de l'or: povoir et territoires urbains au Minas Gerais (Brésil, XVIII siècle), Paris, Fundação Calouste Gulbenkian, 2003 (versão publicada da tese defendida na École des Hautes Études en Sciences Sociales de Paris, em 2001).
} 
nia assentado na estrutura urbana e de que maneira as cidades articularam e configuraram uma rede de poder. Cláudia Damasceno destaca o papel político das câmaras municipais e das elites assentadas nas mesmas, na sua relação com o poder central, ao encaminharem e viabilizarem os interesses locais. A mesma autora publicou um artigo no número 29 da Revista Varia Historia, no qual trata especificamente do tema da concessão de títulos de vila e cidade na capitania de Minas Gerais. As reivindicações pró ou contra estas concessões eram encaminhadas pelas câmaras locais. Os estudos tradicionais atribuíam ao rigor metropolitano a escassez de vilas e cidades em Minas Gerais, ao longo do século XVIII. Durante todo o século, foram elevadas apenas 13 vilas, sendo que somente uma delas se tornou cidade (Mariana), a despeito da estrutura eminentemente urbana da capitania em oposição ao litoral agrário-açucareiro. A autora aponta que, ao contrário do que usualmente se acreditava, muitas vezes, foram as próprias câmaras municipais que obstaculizavam a fragmentação de seu termo, impedindo a implantação de novas vilas. Os discursos contidos nos documentos apresentados pelas câmaras mineradoras às autoridades metropolitanas, que versam sobre a questão, refletem os interesses e as disputas dos moradores locais pela autonomia ou não dos espaços urbanos, imprimindo novos significados aos conflitos entre o poder local e o central. ${ }^{30}$

O segundo é o livro Homens de negócio, de minha autoria. ${ }^{31} \mathrm{O}$ capítulo 4 aborda o comércio em Minas Gerais e destaca o papel das câmaras municipais para efetivar a política de abastecimento na capitania, bem como para o controle das atividades comerciais, fiscalizando as lojas, garantindo a aferição de pesos e medidas, tabelando os produtos, promovendo o fornecimento de carne e outros víveres, evitando açambarcamento de produtos etc. ${ }^{32}$ Para tanto, esta parte do texto utiliza como fonte documental principal exatamente as Atas da Câmara de Vila Rica. As câmaras, atuando intensivamente sobre as atividades comerciais, garantindo o abastecimento dos núcleos urbanos da capitania, constituíram-se em veículo importante para a interiorização da metrópole na colônia. O terceiro é a tese de Flávio Marcus da Silva, Subsistência e Poder,

${ }^{30}$ Cláudia Damasceno Fonseca, "Funções, hierarquias e privilégios urbanos - a concessão dos títulos de vila e cidade na capitania de Minas Gerais", Varia Historia, Belo Horizonte, n. 29, p. 39-51, 2003.

${ }^{31}$ Júnia Ferreira Furtado, Homens de negócio: a interiorização da metrópole e do comércio nas Minas setecentistas, São Paulo, Hucitec, 1999 (versão publicada da tese defendida na USP, em 1996).

${ }^{32}$ Júnia Ferreira Furtado, "O comércio nas Minas”, in: Homens de negócio: a interioriæação da metrópole e do comércio nas Minas setecentistas, p. 197-216. 
recentemente publicado como livro, ${ }^{33}$ cujo cerne é examinar a política administrativa voltada para garantir o abastecimento da capitania de Minas Gerais. $\mathrm{O}$ autor aponta para o alto grau de intervencionismo destes agentes, sendo um desses vetores as câmaras municipais. A ação das câmaras sobre as práticas comerciais, o comércio volante das negras de tabuleiro, as vendas de morro e as vias de comunicação, coibindo a ação dos atravessadores e quilombolas, para, desta forma, garantir o abastecimento, são desnudadas, especialmente nos capítulos 5 e 6, configurando o que ele chama de uma economia do bem comum. Para tanto, o autor examina particularmente os casos de Vila Rica e Lisboa, estabelecendo comparações entre as duas. ${ }^{34}$ Em parte de seu texto, Maria de Fátima Gouvêa destaca a importância da Câmara de Vila Rica para a fiscalização do comércio, garantindo o abastecimento do núcleo urbano, podendo ela ter se valido destas duas análises mais verticalizadas acerca da ação da câmara local sobre a política comercial e de abastecimento do núcleo urbano de Vila Rica.

O eixo central do Homens de negócio, anteriormente mencionado, é a análise das relações de poder que se estendiam desde o reino, a partir do estudo das redes comerciais informais, configurando um sentido de pertencimento dos súditos ao Império português. Como salienta Maria de Fátima, essa nova forma de abordagem das relações de poder no Império passou a marcar os estudos sobre a capitania de Minas Gerais, no século XVIII. Dentro deste escopo de análise, ela destaca duas teses de doutorado recém-defendidas na ocasião, que em muito contribuíram para o entendimento da maneira como se configurou a administração na capitania mineradora, inseridas aí as câmaras municipais, especialmente a de Vila Rica. Trata-se de Governo de Mineiros: de como meter as Minas numa moenda e beber-lhe o caldo dourado - 1693 a 1737, de Maria Verônica Campos, e Administração, justiça e relações de poder: ouvidorias de comarcas nas Minas setecentistas, de autoria de Maria Elisa de Campos Souza. ${ }^{35}$ Conforme Maria Verônica Campos, a cisão da elite em vários grupos,

\footnotetext{
${ }^{33}$ Flávio Marcus da Silva, Subsistência e poder: a política do abastecimento alimentar nas Minas setecentistas, Belo Horizonte, Ed. UFMG, 2008 (versão publicada da tese defendida na UFMG, em 2002).

${ }^{34}$ Flávio Marcus da Silva, Subsistência e poder: a política do abastecimento alimentar nas Minas setecentistas, p. 110-184.

${ }^{35}$ Maria Verônica Campos, Governo de Mineiros: de como meter as Minas numa moenda e beberIhe o caldo dourado - 1693 a 1737, São Paulo, USP, 2002 (tese, Doutorado em História); Maria Elisa de Campos Souza, Administração, justiça e relações de poder: ouvidorias de comarcas nas Minas setecentistas, Niterói, UFF, 2000 (dissertação, Mestrado em História).
} 
cuja convivência nem sempre era pacífica, criou diferentes possibilidades de articulação e negociação entre eles. A Coroa apresentou-se seguidamente como árbitro destas disputas, privilegiando a cada momento os diferentes setores conforme seus interesses mais imediatos. Estas elites articulavam-se em polos de interesse, cuja territorialidade extrapolava a própria capitania. Também Maria Elisa de Campos Souza salienta a importância da prática da negociação na ação administrativa, típica da concepção corporativa de poder sob o signo do Antigo Regime.

Maria de Fátima Gouvêa se vale das análises das duas autoras para chamar a atenção para o fato de que as câmaras municipais foram importantes locus para a articulação destas elites, organizadas a partir de redes de interesse. Foram também significativos espaços de negociação entre o poder local e o poder central. Por fim, salienta o ineditismo da colonização do território minerador para além do binômio da plantation açucareira monocultora que caracterizara a colonização do litoral brasileiro. Ela relaciona a implantação da estrutura camarária no processo de povoamento da região mineradora, marcado por conflitos e pela lenta afirmação da Coroa na região. Destaca que a organização político-administrativa implantada, da qual as câmaras municipais serão peças importantes, permitiu que esta efetivasse a colonização e a conformasse segundo seus interesses, apaziguasse conflitos e garantisse a tributação sobre a produção aurífera.

A partir da análise de como se deu o estabelecimento da administração portuguesa na capitania, Maria de Fátima Gouvêa salienta o processo de progressiva centralização administrativa que vai ocorrendo em torno de Vila Rica, ainda que o estatuto de cidade tenha sido concedido apenas a Mariana. Em meados do século, a vila sediava todas as principais instituições administrativas da capitania, abrigando inclusive a sede do governo. Ao mesmo tempo, devido ao seu conhecimento acerca das instituições camarárias, ela destaca o fato de que, por vários motivos, a Câmara de Vila Rica apresentava uma organização singular no contexto do Império: "trata-se de uma câmara que desde muito cedo havia sido instituída sob a severa vigilância dos oficiais da Coroa", especialmente o ouvidor e o governador. ${ }^{36}$ Neste aspecto, destaca o fato de ali jamais ter sido criado o cargo de Juiz de Fora, sendo que, muito

\footnotetext{
${ }^{36}$ Maria de Fátima Silva Gouvêa, "Dos poderes de Vila Rica do Ouro Preto - notas preliminares sobre a organização político-administrativa na primeira metade do século XVIII", p. 129.
} 
precocemente, desde 1696, tal cargo já fora criado nas Câmaras da Bahia, Rio de Janeiro e Pernambuco. ${ }^{37}$

Aspecto importante em relação à organização camarária da região mineradora que ela chama a atenção foi o papel central que elas desempenharam na cobrança dos tributos, especialmente o quinto do ouro. Principal imposto cobrado na capitania, nesse aspecto, as câmaras souberam encaminhar, defender e negociar com a Coroa os interesses das elites locais, a despeito da fome tributarista da primeira. Isto aponta, segundo a autora, para a abrangência dos poderes arregimentados pelos camaristas em Minas Gerais, para além das questões mais imediatas de organização da urbe, atribuições que lhe eram costumeiras.

Maria de Fátima Gouvêa destaca que, durante boa parte do século XVIII, as disputas entre emboabas e paulistas marcaram a vida da capitania, refletindo na política administrativa estabelecida na região, inclusive nas câmaras municipais. A capacidade destas últimas de negociar em prol dos interesses locais também é destacada pela autora. Esses dois fatos, segundo ela, podem ter contribuído para despertar nas autoridades metropolitanas uma desconfiança em relação ao poder de ação das câmaras mineiras, contribuindo para que a administração metropolitana não introduzisse mudanças que pudessem aumentar seu poder de fogo. Ela sugere que isto poderia ter contribuído para que Vila Rica jamais fosse elevada a cidade, a despeito das reivindicações dos camaristas, ou que o cargo de Juiz de Fora fosse instituído, pois ambas as ações promoveriam a ascensão da câmara, aumentando sua capacidade de negociação.

A partir deste pequeno balanço, Maria de Fátima Gouvêa levanta cinco pontos instigantes sobre os quais os estudos sobre a Câmara de Vila Rica poderiam se guiar e se valer para verticalizar a análise do tema. As sugestões que ela aponta continuam atuais e merecem ser perseguidas por aqueles que se interessarem pelo tema. Em primeiro lugar, examinar mais atentamente os aspectos que inferem singularidade a esta instituição camarária, quando comparada com as demais câmaras do Império. A seguir, mapear as relações estabelecidas entre Vila Rica e as demais vilas da capitania e de que maneira a câmara local articulou e dinamizou as relações jurisdicionais entre elas. Outro tema que, segundo ela, deveria merecer consideração é a política de concessão

\footnotetext{
${ }^{37}$ Maria de Fátima Silva Gouvêa, Frazão e Santos, "Redes de poder e conhecimento na governação de império português, séculos XVI e XVII", Topoi, Rio de Janeiro, v. 5, n. 8, p. $101,2004$.
} 
ou não de privilégios à Câmara de Vila Rica e como tal política refletiu o embate entre os interesses locais e o central. ${ }^{38} \mathrm{Um}$ quarto tema a ser investigado de maneira mais vertical é exatamente a inexistência da nomeação de um Juiz de Fora, inquirindo as razões e as consequências deste ato. Por fim, investigar mais a fundo o papel dos ofícios régios e de que maneira os camaristas de Vila Rica se articularam à administração ultramarina de maneira geral.

\section{Conclusão}

É no interior das interpretações que Maria de Fátima Gouvêa tece em relação a temas mais amplos como as relações de poder, as formas de governação e o estabelecimento de redes governativas no interior do Império português, que suas análises sobre as instituições camarárias se situam. ${ }^{39}$

Seus diversos textos - alguns deles aqui analisados - trouxeram instigantes e importantes contribuições sobre o papel das câmaras municipais no interior do Império marítimo português. Como vimos, ao longo de seus diversos estudos, as câmaras se apresentam como locus de articulação entre o poder local e o central, de distinção da elite governativa, de gestão do espaço da cidade, de hierarquização de poder no seio de diversas instituições. São espaços de negociação, mas também são espaços de conflito - conflitos que se dão entre diferentes setores da elite ou entre a própria elite e a Coroa.

A maior parte de suas análises tomou como ponto de partida a Câmara do Rio de Janeiro na transição do século XVIII para o XIX, particularmente no contexto da transmigração da Corte para a cidade. Porém, como tentei destacar, não se trataram de meros estudos de caso: a todo momento, ela procurou articular o específico ao geral, isto é, conectar sua análise do que se passava no Rio de Janeiro para, com isto, aprofundar o entendimento da ação e constituição das câmaras municipais no espaço alargado do Império, no que cada uma tem de específico e no que todas têm em comum. É este diálogo permanente entre o geral e o particular que permite que, ao focar o estudo da Câmara de Vila Rica no século XVIII, ela traga importantes contribuições para seu entendimento. Mas não só. Generosamente, Maria de Fátima levanta

\footnotetext{
${ }^{38}$ Para este tema ver os trabalhos de Cláudia Damasceno Fonseca já citados.

${ }^{39}$ Como exemplo: Maria de Fátima Silva Gouvêa, "As bases institucionais da construção da unidade. Dos poderes do Rio Joanino: administração e governabilidade no império lusobrasileiro", p. 707-752 e Maria de Fátima Silva Gouvêa, Frazão e Santos, "Redes de poder e conhecimento na governação de império português, séculos XVI e XVII”, Topoi, Rio de Janeiro, v. 5, n. 8, p. 96-137, 2004.
} 
diversos aspectos e temas que ficam como sugestões para que outros autores as explorem em novos estudos.

A herança que Maria de Fátima Silva Gouvêa deixa sobre as câmaras e o poder local é rica e profícua. Suas análises são pontos de partida incontornáveis para quem se aventurar no estudo do tema no espaço do Império português, tanto no aspecto teórico-metodológico, quanto temático. 